\title{
OBJETIVIDAD MORAL Y POLÍTICA
}

Juan Ormeño Karzulovic*

Universidad de Chile

RESUMEN: El autor analiza la distinción entre lo subjetivo, lo objetivo y lo mayoritariamente subjetivo; y las dificultades que genera confundir uno con el otro en el contexto de una sociedad que se considera pluralista y democrática. De este modo, el autor busca enunciar cómo puede operar un Estado que requiere del consenso mayoritario entre sus ciudadanos - al menos en cuanto a una forma de gobierno determinada- y a su vez respetar su libertad de conciencia y permitir el flujo constante de ideas y valores contrapuestos; hallando la respuesta en la necesidad de una constante exigencia de negociación y argumentación racional de los fundamentos que inspiran la acción de cada integrante.

PALABRAS CLAVE: Objetividad moral - objetividad y subjetividad - Democracia y pluralismo libertad de conciencia.

ABSTRACT: The author analyzes the distinction between the subjective, objective and the mainly subjective; and the difficulties that generates to confuse them with one another in the context of a society that is considered pluralistic and democratic. In this way, the author seeks to state how a State that requires majority consensus among its citizens can operate -at least in regards to a determined form of government, and at the same time, respect the freedom of conscience and allow the constant flow of ideas and conflicting values; finding the response on the need for a constant demand for negotiation and rational arguing of the motivations that inspired the action of each person that composes it.

KEYWORDS: Moral objectivity - objectivity and subjectivity - democracy and pluralism - freedom of conscience.

"Pero el derecho objetivo es, esencialmente, también algo subjetivo para sí, es decir no es una piedra, algo exterior, puramente sólido, sino que es la voluntad del espíritu -del espíritu universal, de la formación universal".

Nota manuscrita de Hegel al $\$ 57$ de su ejemplar de la Filosofía del Derecho.

\footnotetext{
* Doctor (c) en Filosofía, Universität Tübingen; Licenciado en Filosofía, Pontificia Universidad Católica de Chile. Profesor de las Universidades de Chile (Derecho) y Diego Portales (Humanidades).
} 
Se suele admitir sin mayor discusión que un rasgo característico de las sociedades modernas -esto es, complejas, en las que la autoridad se apoya en reglas y leyes racionalmente justificables en lugar del carisma, la costumbre o la religión- es un cierto pluralismo de valores, fines, metas y planes de vida, que cada individuo o grupo puede sostener en contra de distintas opciones tomadas por otros. Si esta sociedad moderna, además, está democráticamente organizada, entonces ese pluralismo debe ser aceptado, al menos hasta el punto en que ello no conlleve una destrucción del orden democrático y del Estado de Derecho. En el contexto de esta presuposición, se plantea la pregunta por el status de esa limitación: ¿se trata de una limitación puramente procedimental, y por tanto valorativamente neutra, o de una limitación substantiva -es decir, comprometida con la verdad y objetividad de los valores de la tolerancia, la democracia y el derecho? Si la organización política debe ser moralmente neutra, entonces ella debería ser compatible con un extendido escepticismo moral-del que, por lo demás, muchos liberales hacen gala, como un último baluarte de la libertad individual contra las pretensiones homogeneizadoras del Estado. El problema de esta postura es que convierte los principios morales en los que se asienta el Estado democrático de Derecho en una cáscara vacía, en la que efectivamente las convicciones morales particulares (por ejemplo, las de los jueces y representantes; las de los dueños de los medios de comunicación y las de los 'expertos') se presentan como 'objetivas' sin justificación alguna o, más razonablemente, con justificaciones espurias. Frente a esto, debería ser tentador tratar de reivindicar para la base moral de la democracia y del Estado de Derecho su status de objetiva o verdadera. Sin embargo, el problema de semejante posición es que, aparentemente, hace imposible la controversia y, por tanto, el pluralismo que se quería preservar.

En el presente trabajo me propongo, en primer lugar, ofrecer un sentido plausible para la expresión objetividad moral. Creo que es necesario hacer esto porque, de acuerdo con lo ya señalado, dicha expresión sugiere, a primera vista, dos ideas con las que parece razonable estar en desacuerdo. La primera de ellas se apoya en la contraposición que establecemos normalmente entre lo que es subjetivo y lo que es objetivo: es subjetivo (o, incluso, puramente subjetivo) aquello que le parece verdadero a un agente en particular, pero no a todos $-\mathrm{y}$ supuestamente lo que les parece verdadero a todos, sería objetivo. Sin embargo, dado que todos es una palabra que hay que entender en sentido distributivo -es decir, haciendo referencia a cada uno de los agentes particulares- lo que a cada uno de ellos les parezca verdadero no deja de ser, en última instancia, subjetivo $-\mathrm{O}$, como es moda decir, es intersubjetivamente verdadero. Parece, pues, que por objetivo debiéramos entender algo más fuerte que lo que nos parece verdadero a todos. Algo, entonces, sería objetivamente verdadero cuando su verdad es del todo independiente de su aceptabilidad universal (es decir, su verdad es independiente del modo en que podemos establecerla). Semejante postura puede ser llamada realismo (o, como la ha llamado Putnam de modo feliz, "epistemología del ojo de Dios"1) y es hoy lo suficientemente controvertida como para ser considerada con recelo.

La segunda idea sugerida por la expresión objetividad moral es una extensión natural del realismo hacia el terreno de la moral: parece tener sentido contraponer lo que le parece bueno a

${ }^{1}$ Putnam, HiLARY, Razón, verdad e historia, España, edit. Tecnos, 1988 
un agente particular con lo que es objetivamente bueno, donde esto último parece indicar no tanto lo que les parece bueno a todos sino más bien lo que es bueno en sí mismo. Por incomprensible que pueda parecernos esta última expresión, no podemos dejar de reconocer que apunta en una dirección correcta. En efecto, una comunidad moral completa podría concordar en que algunos de sus miembros son inferiores, incluidos los propios afectados, sin que eso le parezca objetivamente bueno a un observador que no pertenezca a esa comunidad. En su propia comunidad moral, semejante observador puede distinguir entre un sentido convencional de lo que se considera bueno -aquello en lo que todos parecen estar de acuerdo- y lo que es bueno en un sentido moralmente objetivo. En última instancia, dicho observador podría incluso cuestionar si acaso lo que su comunidad llama moralmente objetivo lo es realmente y, para comprobar esto último, buscar un estándar moral que esté por sobre toda comunidad moral contingente. De este modo, lo moralmente objetivo podría ser algo cuya bondad sea independiente de si la gente lo acepta como tal o no. Convengamos en denominar semejante postura como realismo moral. $\mathrm{Al}$ respecto, podría considerarse que este tipo de realismo puede ser igualmente controvertido.

Creo que tanto el realismo epistémico como el moral pretenden levantarse como baluartes frente al escepticismo, a pesar de que, paradójicamente, lo suscitan. Contra esta comprensión de lo que sea la objetividad moral quisiera defender otra, de menores pretensiones, pero potencialmente más robusta; que se haga cargo del carácter de negociación permanente que tiene la vida moral en sociedades complejas. Luego de haber hecho esto, exploraré brevemente si la objetividad moral, así entendida, debe tener relevancia para la discusión pública.

\section{II}

La conducta de un agente libre, así como los principios que la guían, pueden ser evaluadas en función de si hacer $x$ es bueno/malo. Esta evaluación puede ser llevada a cabo tanto por el propio agente como por otros actores y desde distintos puntos de vista: el agente puede considerar (1) que hacer $x$ es bueno/malo para sí mismo. Este es un punto de vista en el que otros actores también pueden situarse (vgr. (2) “hacer $x$ es bueno/malo para él"). Los demás pueden juzgar la acción del agente en función de si (3) lo que él hace es bueno/malo para ellos; y el propio agente puede situarse en ese punto de vista y evaluar su acción en función de (4) si lo que él hace es bueno/malo para los demás. Los tres primeros puntos de vista pueden ser juicios evaluativos relativos a la mera racionalidad de la acción y son perfectamente compatibles con una postura egoísta, cuyo propósito sea la promoción del propio interés. El cuarto punto de vista, en cambio, sugiere que en la evaluación que el propio agente hace de su acción, los demás - esto es, los intereses de los demás- son tomados en consideración. Este es el punto de vista moralmente relevante.

Solemos pensar que una acción cumple con los estándares moralmente apropiados cuando ella favorece a los demás o, al menos, no los perjudica. Si en cambio la acción -o, a veces, la omisión-, los daña, solemos pensar que esa acción es inmoral; es decir, tenemos el deber de realizar aquellas acciones nuestras que favorezcan los intereses moralmente 
permisibles de los demás; y tenemos licencia para realizar todo aquello que no los perjudique, mientras que nos está prohibido (o tenemos el deber de evitar) realizar acciones que los dañen. No obstante, considerando que cuando actuamos estamos interesados en realizar nuestros propios fines y que a veces preferimos nuestro caso al de los demás, es obvio que no siempre cumplamos con dichos estándares. Sin embargo, no veo en ello ningún motivo especial de controversia, con excepción de aquello relacionado con adjudicar culpas y responsabilidades en cada caso. Este tipo de controversia difícilmente podría suscitar alguna apelación al pluralismo, como tampoco podría suscitar la necesidad de cierta objetividad moral. Controversias moralmente significativas, en cambio, pueden darse cuando a alguien que cree estar haciendo lo moralmente permisible -por ejemplo, cuando ejerce un derecho para el que cree tener títulos-, se le imputa por ello mismo estar causándole un daño a otro -es decir, se le imputa estar haciendo lo que no debe o se le niega la titularidad del derecho que creía tener. Ciertamente, bajo esta forma podrían considerarse los meros conflictos de interés, donde lo que se disputa es la titularidad de un derecho reconocido. Sin embargo, ciertos conflictos sociales tensionan los consensos existentes en una comunidad dada mucho más allá de los límites del derecho vigente. Característicamente, semejantes conflictos demandan reconocimiento de derechos (putativos) hasta entonces negados, cuyo reconocimiento implicaría la limitación o la negación de derechos hasta ahora positivamente protegidos.

Este tipo de conflictos puede ser ilustrado si mencionamos, a modo de ejemplo, las demandas de los trabajadores subcontratados de la gran minería del cobre en Chile. Estos trabajadores - contratados por una empresa $X$, que a su vez es contratada por la empresa $Y$, para la ejecución de ciertas tareas- realizan la misma labor que el personal de planta de la empresa contratante, por sueldos más bajos y sin ninguna de sus garantías. Creen -con razóntener derecho a igual salario por el mismo trabajo, y al demandarlo, fuerzan el conflicto en dirección a la negociación por rama de la producción, negando así el derecho laboral vigente y la sabiduría inveterada de ciertos economistas. En el caso de las mujeres que tienen una demanda similar, en cambio, su reivindicación no sólo es justa, sino además legal: su derecho es reconocido, aún cuando no sea respetado.

Creo que este tipo de controversias pueden redefinir los términos en los que una comunidad moral y jurídica entiende lo moralmente debido y lo permisible, esto es, lo que les debemos a los demás. Sin embargo, este tipo de conflictos tampoco parece suscitar la cuestión del pluralismo, quizá porque las partes en pugna suelen apelar a valores que ambas comparten, aunque los interpreten de manera contrapuesta. Si esto es correcto, este tipo de conflictos revelan una cierta objetividad moral que se da por sentada.

Otro tipo de controversia moral significativa lo constituye el conflicto valorativo. Sin embargo, de la mera existencia de una diversidad de valores no se sigue necesariamente un conflicto entre ellos. Es un hecho que distintos agentes aceptan, como principios para elegir acciones, valores (metas, estilos de vida, concepciones de la vida buena, etc.) que son incompatibles entre sí. Por sí mismo, este hecho no debiera generar ningún tipo de controversia, pues si las acciones que los agentes seleccionan en función de esos valores son moralmente permisibles (es decir, no dañan a los demás) no amenazan con controvertir nuestros consensos normativos. Tampoco es motivo de controversia moral que alguien trate de convencer al resto de que los valores que ha escogido seguir tienen un valor intrínseco y merecerían ser escogidos también por todos los demás. El problema se presenta cuando un 
agente trata de imponer sus convicciones a quienes no las comparten, lo que ocurre, por ejemplo, cuando quiere que los marcos legales que regulan la conducta de todos se ajusten a los valores que él sostiene. ¿Es esto moralmente permisible? Ciertamente no, si asumimos, como debiéramos hacerlo, que la conciencia individual es un santuario que sería anatema violar. Esta proposición expresa, también, la adhesión a un valor -el de la universal libertad de conciencia. Sin embargo, chay alguien que seriamente argumente en público en contra de dicha proposición? La estrategia para imponer ciertos juicios valorativos por la vía judicial -y, al mismo tiempo, presentarlo como una legítima controversia moral-, consiste en restringir ciertas acciones, privadas o públicas, para cautelar los intereses de terceros. A primera vista, esta es una estrategia extraña pues ¿quién más autorizado que los eventuales afectados por esas acciones para determinar si ellas perjudican sus intereses o su bienestar? Esto sólo nos parece aceptable cuando los potenciales afectados no están en condiciones de determinarlo (digamos, personas incapacitadas para hacerlo, niños en el vientre de sus madres o, también, las generaciones futuras; pudiendo incluso mencionar la honra de personas muertas, pero este caso puede ser más exótico ${ }^{2}$. Pero si la consideración moralmente relevante es la que hace el propio agente en función de los intereses de los demás, ¿'es moralmente permisible que otros agentes lo fuercen a ser moral?

Consideremos estos puntos desde otra perspectiva: ciertamente no debemos cautelar todos los intereses de los demás cuando los tomamos en cuenta al evaluar nuestras acciones, sino sólo aquellos moralmente permisibles, esto es, los que no perjudican los intereses del resto. Ahora bien, para hacer esto no es indispensable tener en cuenta el contenido de esos intereses, pero sí la capacidad de los demás para perseguirlos. Así, como tenemos el deber moral de no obstaculizar por medio de nuestra acción la persecución que los demás hagan de sus intereses legítimos, tenemos el deber moral de promover su capacidad para hacerlo (así podría en principio justificarse moralmente la vida del no nacido, por ejemplo, en la medida en que la vida es condición del ejercicio de la libertad, pero convertirlo en ley restringiría las condiciones del mismo ejercicio para una persona actual). Análogamente, no tenemos el deber moral de compartir las convicciones o valores que razonablemente otros puedan sostener, pero sí podemos apreciar como un hecho moral relevante y significativo la capacidad que cada agente tiene de conferir valor, o de formarse una concepción del bien, a partir de la cual seleccionar un plan de vida o acciones particulares. Por tanto, podemos considerarnos moralmente compelidos a resguardar la libertad de conciencia y a considerar la vida que cada uno lleva según sus dictados como expresión de una vida personal auténtica y, de este modo, considerar que tenemos el deber moral de resguardar la diversidad. Pero nada más.

Ahora bien, las controversias morales sólo pueden ser significativas -al menos así lo creo- cuando se producen en el seno de algún acuerdo fundamental: de no ser así, no habría, propiamente hablando, controversia, sino sólo discursos y demandas que aparentan hablar de lo mismo, pero que, en realidad, corren por vías paralelas sin punto de contacto. Alguna idea de lo que es "moralmente objetivo" podría llenar el lugar vacío de semejante "acuerdo" necesario. Pero espero haber sugerido que los términos de ese acuerdo no pueden consistir en la fijación arbitraria de lo que le debemos a los demás o en alguna concepción acerca de lo que

\footnotetext{
${ }^{2}$ Caso: prohibición de exhibir la película La última tentación de Cristo, porque se lesionaba no sólo la honra de los creyentes, sino también la del propio Jesús.
} 
es bueno, pues ambos casos son materia de controversia. Al contrario, creo que el mejor candidato para ocupar ese lugar es algo así como la exigencia absolutamente recíproca de justificación racional -inserta, precisamente, en el corazón de las controversias-, que es inseparable de una concepción de nosotros mismos como agentes libres, lo que equivale a decir que la vida moral moderna tiene el carácter de una permanente negociación, cuyo único criterio es el mutuo reconocimiento

En efecto, nos hallamos siempre inmersos en una red de demandas que apelan a nuestro carácter de agentes libres y racionales (esto es, agentes que, por un lado, se consideran a sí mismos capaces de haber siempre obrado de una manera distinta y, por otro, agentes que pueden dar cuenta de cuáles son los principios, normas o criterios que gobiernan su conducta -en que la expresión "agente" se refiere a un sujeto que es capaz de ponerse fines y orientar su acción en función de ellos). Quiero decir con esto que somos agentes a los que los otros están constantemente exigiendo razones, excusas, etc., y que las considerarán como buenas/malas, pertinentes, aceptables, etc., en función de si pueden comprenderlas y criticarlas.

Por ejemplo: si alguien justifica ante $\mathrm{Ud}$. el desprecio que ha evidenciado en su conducta ante otro, porque considera que ese otro es, digamos, alguien inferior, o alguien que no comparte sus valores, independientemente de que Ud. sienta lo mismo o pueda, siquiera, comprender el sentimiento, puede preguntarse si acaso tal justificación es válida. Su duda en torno a la validez o pertinencia de las razones de la acción se debe a que hemos llegado a comprender que la comunidad moralmente relevante son todos aquellos que pueden pedir razones de las acciones de los otros y, al mismo tiempo, dar razones de su propia acción y que comprenden, además, que uno no está justificado por el hecho de pedir razones si, a su vez, no está dispuesto también a darlas.

Dada la omnipresencia de la demanda moral de los demás sobre su conducta, su sometimiento a ciertas obligaciones éticas, por convencionales que éstas sean, es inescapable. $\mathrm{La}$ “inescapabilidad" no tiene que ver, naturalmente, con que Ud. siempre y en todo lugar cumpla con su obligación. Al fin y al cabo, las obligaciones morales que tenemos para con los demás no son como la ley de gravedad y, dada la diversidad potencial de esa demanda, el que Ud. las cumpla o no puede depender de un constante regateo con los demás $-\mathrm{O}$, incluso, con su propia conciencia, pues en el terreno de la moral la autojustificación, para bien o para mal, juega un rol central. La "inescapabilidad" tiene que ver con que se nos compele una y otra vez a dar cuenta de las razones de nuestras acciones y, a veces, omisiones. Esto sugiere, primero, que la "ética", pese a todo, no es, simplemente, como un almacén donde están en venta diversas ofertas morales, las que puede Ud. comprar o no arbitrariamente. Sugiere además que cualquiera que sea la oferta moral que Ud. haya elegido, a fin de disponer de una batería de principios de acción y juicio, siempre estará abierta a la exigencia del otro de ser comprensible y criticable. Es más, sugiero que la exigencia de objetividad en materia de justificación de principios morales es, ella misma, una de las demandas morales constantes que nos hacemos unos a otros ${ }^{3}$.

\footnotetext{
${ }^{3}$ Quién hace hincapié especial en la cuestión de la objetividad moral es TugENDHAT, ERNST, Vorlesungen ubre Ethik. 1993.
} 


\section{III}

En relación al uso público de la noción de objetividad moral, el problema de los liberales podría frasearse de este modo: la justificación política debe ser compatible con la libertad de conciencia, de modo que no pueden admitirse reglas legales que violen las convicciones morales o filosóficas razonables que los individuos tengan (es decir, no podemos obligarlos a desobedecer a su conciencia porque nosotros - es decir, el Estado o una cierta mayoría moralpensemos que están equivocados). De ahí que la verdad no pueda, según ellos, ser una condición necesaria para la justificación política. Sin embargo, he tratado de sugerir que si la vida moral, e incluso la propia noción de objetividad moral, requieren de permanente negociación, no se ve por qué lo mismo no pueda aplicarse al ámbito público. Si ello no fuere posible, entonces las normas de la política estarían fuera de la discusión moral y, por tanto, no podría tener lugar en ella la controversia a través de la cual llegan a ser admitidos nuevos derechos y obligaciones y se restringen o eliminan otros -que es para lo que está la política, en su aspecto agonal, conflictivo, al fin y al cabo. Y si, así y todo, hubiese que excluir a la política de la discusión normativa dura, entonces no veo por qué los liberales podrían quejarse de las revoluciones, asonadas y motines que, siempre de nuevo, asolan a las tan razonables repúblicas liberales. Ello porque su propia concepción impide, me parece, cualquier reforma substantiva -esto es, aquellas cuya discusión tiene por tema el carácter de las propias normas. La ironía de esta postura es que es prorrevolucionaria a su pesar.

Sin embargo -podría objetarse pragmáticamente- la gracia de la política es, precisamente, procurar un ámbito en el que, de modo regulado, se puedan resolver los conflictos; pues se hace necesario que el marco que hace posible semejante regulación esté por sobre las partes en conflicto. En mi opinión, sin embargo, esta versión cuasi-judicial de la política no puede ser satisfactoria, toda vez que nos exige algo que, independientemente de que sea factible, no es ni siquiera deseable, a saber: que nuestro consenso normativo fundamental esté dado de una vez y para siempre. No es factible, puesto que la propia historia de nuestro consenso en torno a la democracia, la igual dignidad de las personas, etc., no se condice con ella (si tuviésemos que contentarnos con el consenso normativo del siglo XVIII, por ejemplo, todavía tendríamos voto censitario, amplias capas de la población que no gozarían de derechos ciudadanos y ninguna legislación social). Y me parece obvio que no podemos saber a priori cuáles van a ser las demandas normativas del futuro; aquellas que son posibilitadas por nuestro consenso normativo actual (en todo caso, en nuestro estado actual lo que nos falta para tener una sociedad justa es tanto, que la preocupación por las demandas del futuro parece una broma macabra); lo que no es deseable, pues a pesar de que ninguna comunidad política puede subsistir sin algún tipo de orden, semejante orden debe mostrarse capaz de subsistir en el tiempo y, para ello, debe ser capaz de generar la lealtad de los individuos sujetos a él. Una cultura política compartida no debe, simplemente, reflejar nuestro consenso normativo actual, sino también poder estar abierta a su propia potencialidad. Y creo que la mejor manera en la que esto puede ocurrir es imaginándolo como una constante negociación por la (mejor) justificación de nuestras expectativas normativas. Sólo a partir de esto es posible, en función de esa objetividad moral, aceptar algunas demandas normativas como legítimas y rechazar otras como ilegítimas. 
Ilustremos este último punto precisamente a propósito de la libertad de conciencia: ¿Qué privilegio tienen mis convicciones razonables que hacen ilegítimo que se me obligue legalmente a cumplir disposiciones que violen mi conciencia? ¿Y si las convicciones razonables de muchos llevaran a la destrucción de un estado legítimo, no tendría éste el derecho de "forzarlos a ser libres"? Un ejemplo puede ilustrar este punto: el creciente reconocimiento de la importancia de la libertad de conciencia ha llevado a muchos estados democráticos de derecho a subordinar el cumplimiento de ciertas obligaciones políticas a su conformidad con la conciencia individual. Así es posible que hoy un ciudadano no haga el servicio militar o se niegue a ir a la guerra apelando a sus convicciones religiosas o filosóficas. Pero es obvio que este reconocimiento de la libertad de conciencia es parasitario, pues ¿qué pasaría si, en caso de guerra, todos los ciudadanos de un estado legítimo - esto es, un Estado cuya pretensión de autoridad en todas las otras materias puede suponerse que cuenta con el asentimiento de sus ciudadanos- se negaran a defenderlo apelando a sus convicciones religiosas o filosóficas? ¿o tendría este Estado el derecho o incluso el deber de violentar sus conciencias y obligarlos a cumplir con sus obligaciones? 